\title{
Interdisciplinary Treatment of a Fused Lower Premolar with Supernumerary Tooth
}

\author{
Cengiz Gadimlia
}

Zafer Sari ${ }^{b}$

\begin{abstract}
The objective of this report is to describe combined orthodontic and endodontic treatment of a fused mandibular premolar with supernumerary tooth. The patient was a 15 year old girl seeking orthodontic treatment for the correction of maxillary and mandibular crowding. Cephalometric examination revealed skeletally Class I relationship. The panoramic radiograph showed a fused tooth with two separate pulp chambers and two separate root canals connecting in apical third. After the endodontic treatment of the fused teeth, the stripping of the supernumerary tooth was performed to establish a Class I canine relationship and to correct midline deviation. At the end of the treatment, the crowding was resolved and positive overjet and overbite was achieved. (Eur J Dent 2011;5:349353)
\end{abstract}

Key words: Supernumerary tooth; Fusion; Orthodontic treatment; Endodontic treatment.

\section{INTRODUCTION}

Dental anomalies can be classified into different groups such as anomalies of volume, anomalies of number, anomalies of form, anomalies of position and anomalies by union. ${ }^{1}$ Fusion and gemination are developmental anomalies which occur due to the union of one or more adjacent teeth during development. ${ }^{2}$

Fusion and gemination are terms frequently used to describe the clinical presentation of dou-

a Private Practice, Konya, Turkey.

b Professor, Department of Orthodontics, Faculty of Dentistry, University of Akdeniz, Antalya, Turkey.

- Corresponding author: Dr. Cengiz Gadimli Selcuk Universitesi, Dishekimligi Fakultesi Ortodonti ABD, Selcuklu- 42079, Kampus, Konya, Turkey. Phone: + 903322231151

Fax: + 903322410062

E-mail: dr.cengizawindowslive.com ble teeth. ${ }^{2}$ Knezevic et $\mathrm{al}^{2}$ examined 3517 plaster models in order to find the prevalence of double teeth (fusion and gemination) among the individuals tested based on gender, distribution in the maxilla or mandible, and whether the anomaly occurred bilaterally or unilaterally. The results of their investigation on a prevalence of double teeth appeared as $0.2 \% ; 57.2 \%$ of them fused and $42.9 \%$ geminated.

It is generally accepted that fusion results from the conjoining of two teeth buds, while gemination originates when one tooth bud attempts to split into two. ${ }^{3}$ Some authors included geminated teeth among cases of fusion in which union occurred to a supernumerary element. However, it is not known if fusion and gemination are part of the same developmental disturbance, or if they may 
be considered as pathological events leading to the formation of supernumerary elements. ${ }^{4,5}$

Fused teeth are usually found in the mandible, while cases of geminated teeth are more frequently seen in the maxilla. ${ }^{6}$

This paper reports a rare case of a fused mandibular premolar with supernumerary tooth and its treatment with combined orthodontic and endodontic treatment.

\section{CASE REPORT}

The patient was a 15 year old girl seeking orthodontic treatment for the correction of maxillary and mandibular crowding. Extra-oral examination revealed a symmetrically proportionate face and a convex profile (Figure 1).

Intra-oral examination indicated that the patient had an Angle Class I malocclusion with an anterior tete a tete bite, and a midline deviation of $3 \mathrm{~mm}$ to the right at the mandibular dental arch. The left mandibular dental arch presented fused mandibular premolar with supernumerary tooth (Figure 2).

The cephalometric radiograph revealed skeletal Class I relationship (Figure 3). The panoramic radiographic examination disclosed that all the secondary teeth were present but there seemed to be an extra tooth between mandibular left canine and first premolar (Figure 4). The periapical radiography showed a fused tooth with two separate pulp chambers and two separate root canals connected in the apical third area (Figure 5).

The goals of the treatment were as follows:

- Maintain Angle Class I relationship

- Maintain the overjet and overbite

- Correct the midline

- Align the teeth in both arches and achieve good intercuspation.

Maxillary and mandibular fixed appliances (Roth prescription $0.018 " \times 0.025 "$ ) were used. After initial leveling, the fused teeth required nonsurgical endodontic treatment for stripping, which was performed below cemento-enamel junction to correct midline deviation and preserved Class I canine relationship.

\section{DISCUSSION}

When a supernumerary tooth is joined with a permanent tooth, it is clinically hard to distinguish between fusion and gemination. Due to the difficulties about the discrimination of fusion and gemination in the permanent dentition, $\mathrm{Mader}^{7}$ suggested that all permanent teeth joined by dentine should be regarded as fusion. According to Bashkar ${ }^{8}$ gemination occurs when a germ is divided in two but not in total, forming one root and two crowns. On the other hand, in fusion there are two crowns and generally one root with two canals or two roots. Law et al ${ }^{9}$ declares that gemination is a similar dental malformation but consists of one pulp canal and one root, whereas in fusion the teeth are combined by dentine and have independent pulp canals.

The presented case displays a supernumerary tooth combined with the mandibular left first premolar. The clinical and radiographic examination reveals two pulp chambers where the crown and the roots are combined through the dentine and cement level. Moreover, the pulp chambers of these teeth are also joined through the apex level. After the evaluation, this case was regarded as fusion.

It is considered in terms of aesthetic and functional values that the treatment of the fused teeth requires a complicated multidisciplinary approach.

As described in the previous studies, a possible treatment method would be extraction of the tooth after the completion of the canal therapy of the fused tooth, removal of the unwanted part and reimplantation into its original site. ${ }^{10,11} \mathrm{How}$ ever, depending on the information obtained from the previous studies, ankylosis might be expected on the root surface of the reimplanted tooth. This arises due to the lack of periodontal membrane on the root surface. ${ }^{12}$

Taking this information into account, in order to provide proper aesthetics and function, an alternative treatment approach was planned to avoid the ankylosis which may develop after reimplantation of the tooth, where the excess part was removed following the root canal treatment. After performing the canal therapy on the fused tooth, selective stripping was done on the unwanted supernumerary tooth to improve the crowding and the deviated midline.

After the endodontic treatment of the fused teeth, the stripping of the supernumerary tooth was performed to establish a Class I canine relationship and to correct the midline deviation. At 


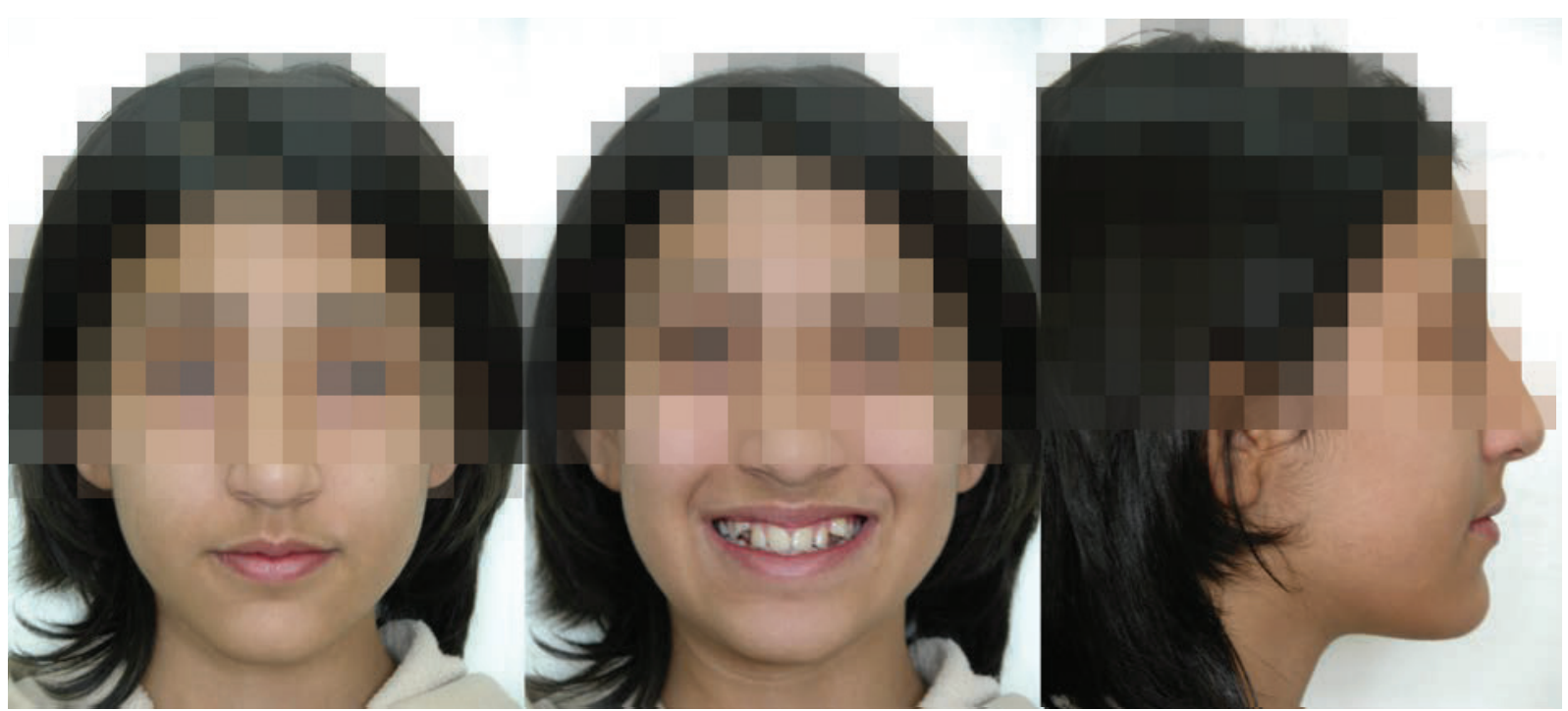

Figure 1. Pretreatment extraoral photographs.

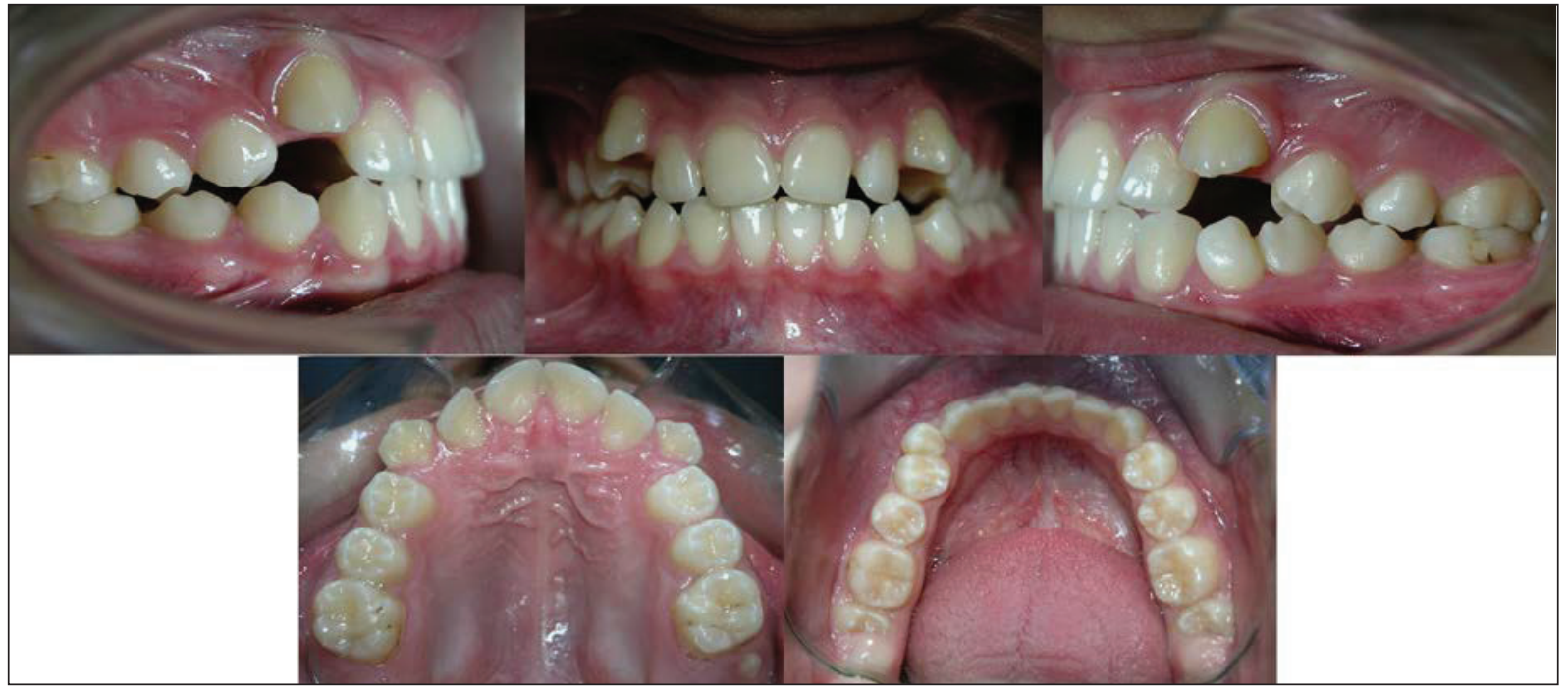

Figure 2. Pretreatment intraoral photographs.

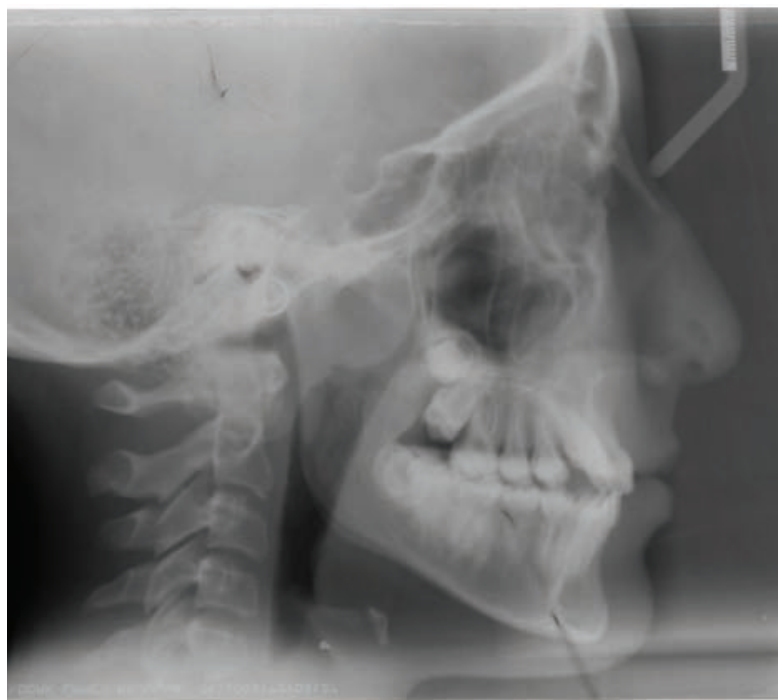

Figure 3. Pretreatment cephalometric radiograph.

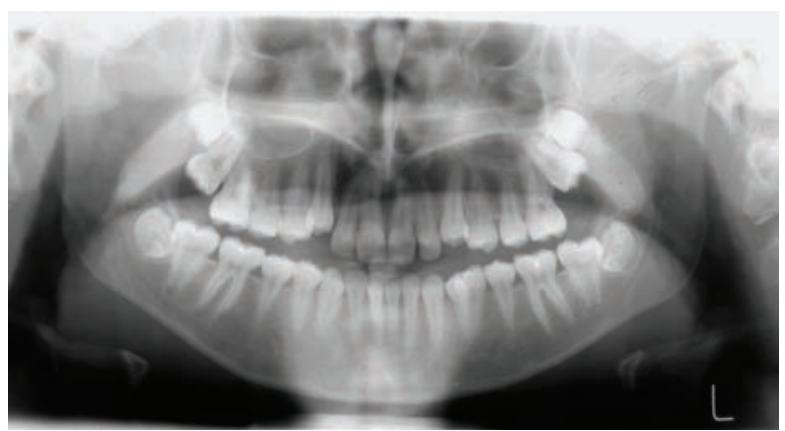

Figure 4. Pretreatment panoramic radiograph.

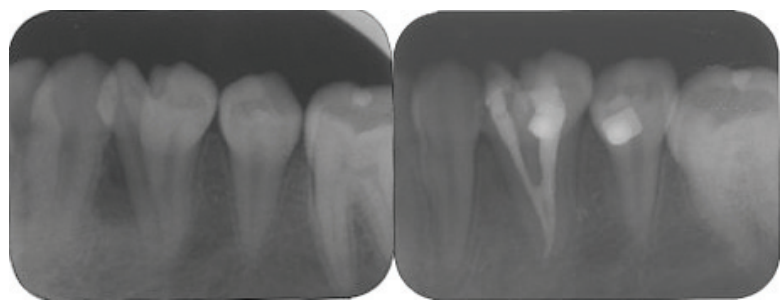

Figure 5. Periapical radiographs before and after endodontic treatment.

ㄱ July 2011 - Vol.5 


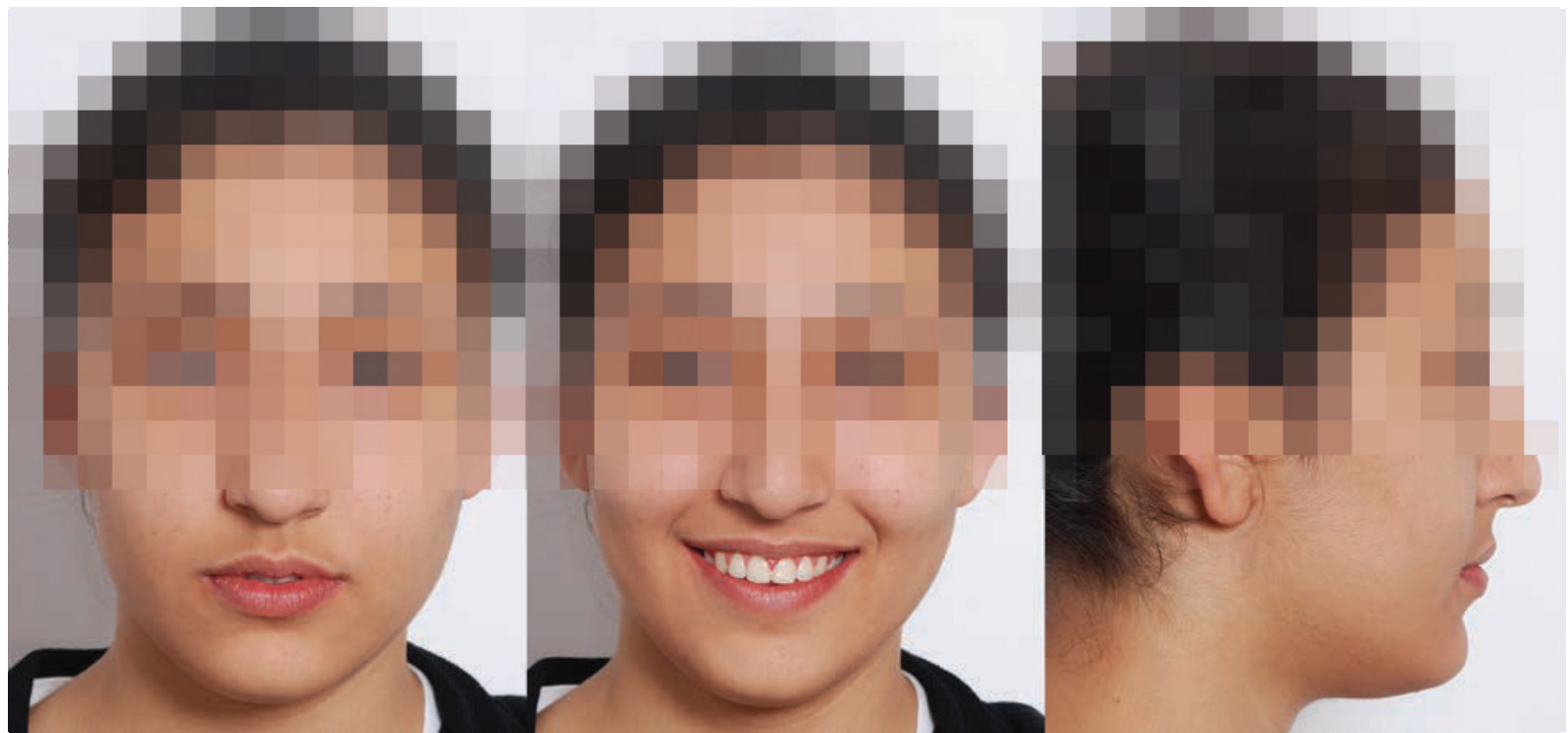

Figure 6. Postreatment extraoral photographs.

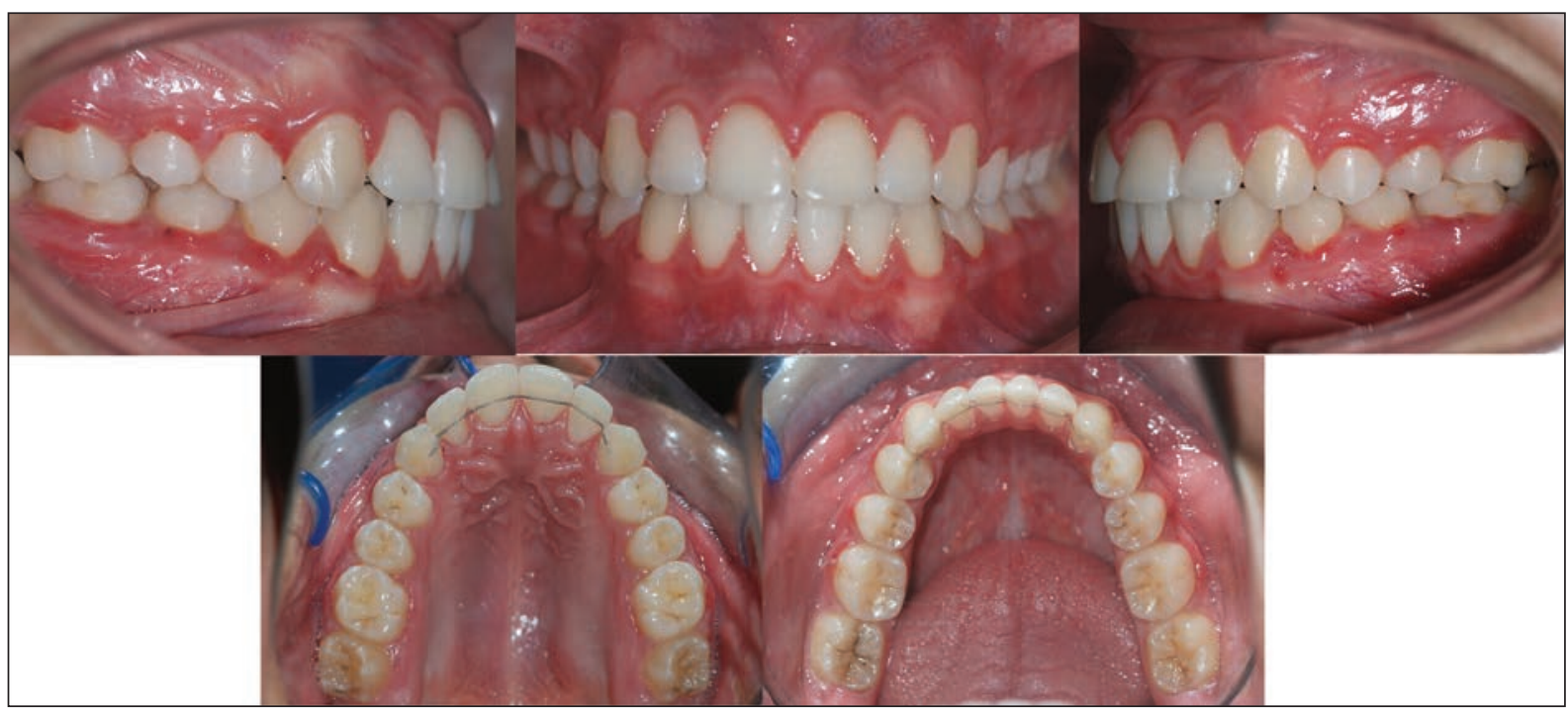

Figure 7. Postreatment intraoral photographs.

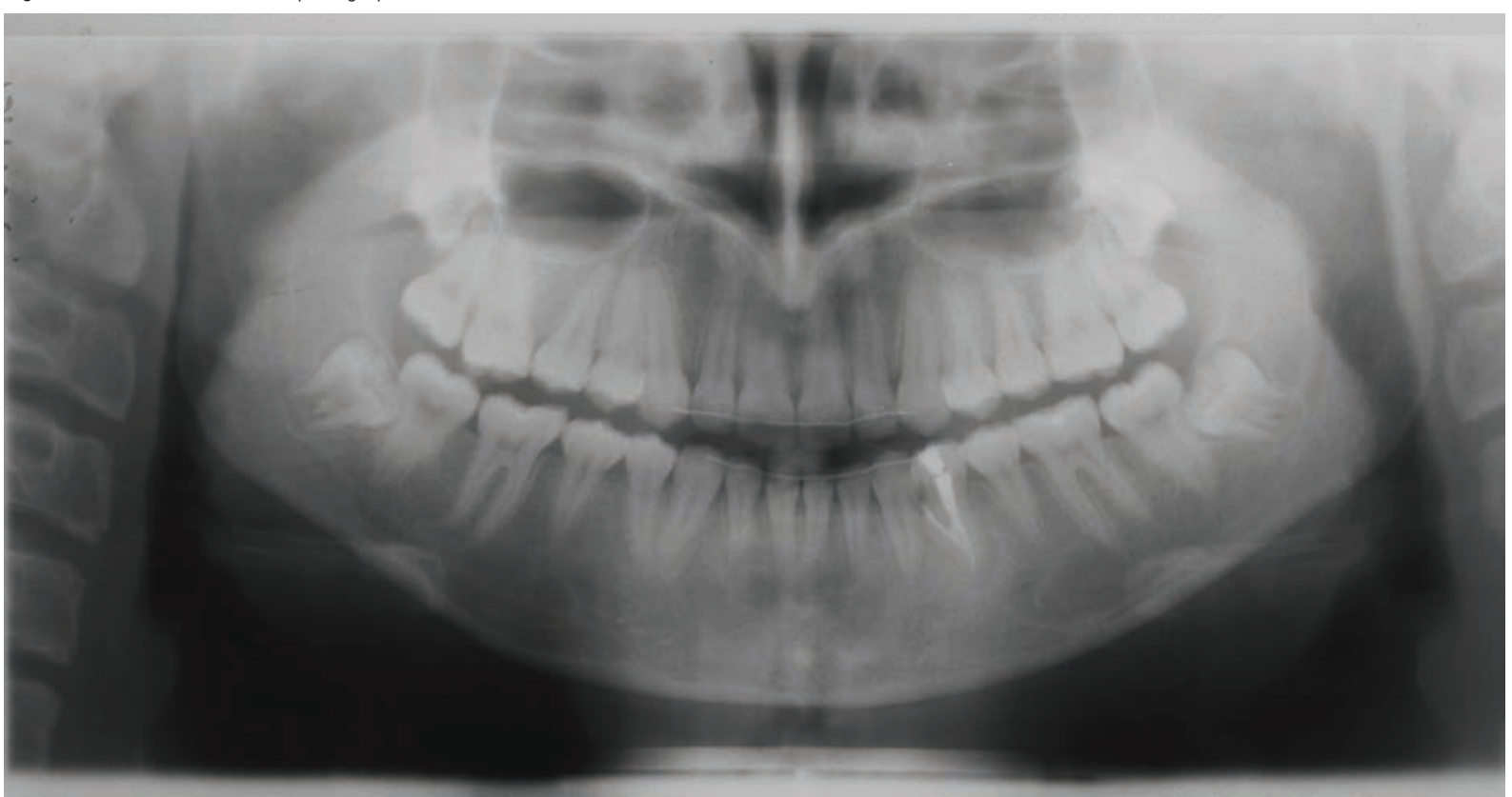

Figure 8. Postreatment panoramic radiograph.

European Journal of Dentistry 
the end of the treatment, the crowding was resolved as well as positive overjet and overbites were achieved (Figures 6, 7 and 8).

After successful endodontic treatment, there was no need for surgical approach. We believe that under normal circumstances, stripping could be performed below cemento-enamel junction. As a result, significantly improved facial appearance with a satisfactory smile, vastly improved occlusion, and increased self-esteem can be achieved.

\section{REFERENCES}

1. Nadal-Valldaura A. Patologia dentaria. Barcelona: Ed. Rondas; 1993. p.55-58. Cited by: Hernandez Guisado JM. Dental gemination: report of case. Medicina Oral 2002;7:231236.

2. Knezevic A, Travan S, Tarle Z. et. al. Double tooth. Coll Antropol 2002;26:667-672.

3. Terezhalmy GT, Riley CK. Gemination/fusion. Quintessence International 1999;30: 437.

4. Carroll MK. Fusion and gemination in alternate dentitions. Oral Surgery 1990;69:655.

5. Gersh RP, Isler S. Bilateral connation of primary molars: repor of case. J Dent Child 1973;40:39-41.

6. Brook $A H$, Winter GB. Double teeth. A retrospective study of "gemination" and "fused" teeth in children. Br Dent $J$ 1970;129:128-130.

7. Mader CL. Fusion of teeth. JADA 1979;98: 62-64.

8. Bashkar B. Radiologia dental Barcelona: Ed. Salvat; 1983;p.338. Cited by: Hernandez Guisado JM. Dental gemination: report of case. Medicina Oral 2002;7:231-236.

9. Law DB. Atlas de odontopediatria. Buenos Aires: Ed. Mundi; 1972;p.66. Cited by: Hernandez Guisado JM. Dental gemination: report of case. Medicina Oral 2002;7:231-236.

10. Blank BS, Ogg RR, Levy AR. A fused central incisor, periodontal considerations in comprehensive treatment. $J$ Periodontol 1985;56:21-24

11. Kayalibay H, Uzamıs M, Akalin A. The treatment of a fusion between the maxillary central incisor and supernumerary tooth: report of a case. J Clin Pediatr Dent 1996;20:237-240.

12. Andreasen JO, Kristerson L. The effect of limited drying or removal of the periodontal ligament: periodontal healing after replantation of mature permanent incisors in monkeys. Acta Odontologico Scandinavica 1981;39:1-13. 